\title{
Urgent Thoracotomy for Blunt Chest Trauma
}

\section{Romaldas Rubikas* and Abdul Rahman Maaliki}

Clinic of Cardiac, Thoracic and Vascular Surgery, Lithuanian Health Sciences University, Lithuania, Europe

\begin{abstract}
The majority of patients with blunt chest trauma are treated conservatively or using minor thoracic surgical procedures, and video-assisted thoracoscopic surgery. However, in a small but significant number of patients an urgent exploration of the chest via, thoracotomy is unavoidable. In those cases thoracotomy means not only a surgical incision, but the most invasive (aggressive) method used in the complex treatment of blunt chest trauma.

The objectives of this study were the following: (2) to specify the indications for urgent thoracotomy, regarding the possibilities of video-assisted thoracoscopic surgery; [2] to reveal the main factors influencing outcomes following urgent thoracotomy.

A retrospective review of 1,826 patients (age $40.3 \pm 12.4$, range $18-79$ years) with blunt chest trauma over the period of 10 years (2002-2011) was performed. A detailed analysis was completed involving 102 (5.6\%) patients who underwent urgent thoracotomy. We recorded patients' age and gender, the mechanism of injury, clinical condition, NISS, injuries of the chest, intrapleural hemorrhage (hemothorax) and air leakage (aeropathic syndrome), methods of treatment, mortality and morbidity occurring within 30 days following urgent thoracotomy. Student's $t$ and chisquared tests were used for the comparison of the data. The level of statistical significance was set at $p<0.05$.

Comparing to the previous period (1987-2000), video-assisted thoracoscopic surgery has reduced twice (to $5.6 \%$ ) the incidence rate of urgent thoracotomy. The overall postoperative morbidity and mortality rate was $65.7 \%$ and $8.8 \%$, respectively. Video-assisted thoracoscopic approach is the method of choice for clinically stable patients. However, when surgical intervention is unavoidable for clinically unstable patients, it should be started with urgent thoracotomy. Multiple fractures of ribs and/or sternum that caused flail chest, injuries of lungs, and intensive intrapleural hemorrhage, resulting in patient's clinically unstable condition were the main factors influencing morbidity and mortality following urgent thoracotomy due to blunt chest trauma.
\end{abstract}

Keywords: Blunt chest trauma; Injury; Hemothorax; Air leakage; Urgent thoracotomy

\section{Introduction}

Discussions concerning the surgical treatment of blunt chest traumas (BCT) are not yet settled, and no "golden" standard exists. Similar diagnostics and treatment methods are applied in different and varying conditions; hence, every clinic has its almost unique experience [1-7]. Any significant progress in this area of thoracic surgery may be achieved only when exchanging our experience. BCT management is a complex process that could not be covered in one study, and thus we focused on urgent decision-making issues. A number of questions arise in the management of BCT, but the key points lie in determining the optimal time, type, and extent of surgical intervention. During the last 12-15 years, Video-Assisted Thoracoscopic Surgery (VATS) has become the main method of BCT treatment [8-14]. However, the decision to explore urgently the chest often still remains a challenge for thoracic and general surgeons. From this point of view, thoracotomy (resuscitative, urgent, early, elective, etc.) means not only a surgical incision, but the most invasive (aggressive) approach in the complex management of BCT [13,15-20]. Since 2001, we organize the management of BCT using a protocol, represented in the form of algorithms that were completed on the basis of our previous clinical experience. Comparing to the previous period (1987-2000), when VATS was not common in our clinic, the incidence rate of Urgent Thoracotomy (UT) has been reduced by half [21,22]. The time has come to specify the indications for UT with respect to the possibilities of VATS, and to reveal the main factors that influence the outcomes.

\section{Material and Methods}

\section{Patients}

The Department of Thoracic Surgery of the Hospital of Lithuanian
University of Health Sciences provides specialized surgical aid for nearly 1 million inhabitants. From the beginning of 2002 to the end of 2011 , we treated 1,826 (age $40.32 \pm 16.44$, range 18 - 89 years) patients who sustained BCT due to traffic (67\%), occupational (25\%), criminal (5\%), and other (3\%) accidents. Only adult patients were included in this study because patients younger than 18 years are treated by pediatric surgeons in our clinic. A detailed retrospective analysis was completed involving all patients who underwent UT.

\section{Management of blunt chest trauma}

BCT management was organized according to our Clinic's protocol presented in the form of algorithms for diagnosis and treatment of most dangerous chest injuries and traumatic syndromes (Figures 1 and 2). The initial actions were the evaluation of the patient's clinical condition, chest and associated injuries, intrapleural hemorrhage (hemothorax) and/or air leakage (aeropathic syndrome).

\section{Assessment of injuries and evaluation of patients clinical condition}

The severity of injuries was assessed using the New Injury Severity

${ }^{*}$ Corresponding author: Prof. Romaldas Rubikas, M.D., Ph. D., FETCS, Eiveni 2 Kaunas 5009, Lithuania, Tel: +370-37-327353; Fax: +370-37-326934; E-mail: romaldasr@email.It

Received October 31, 2012; Accepted November 20, 2012; Published November 22, 2012

Citation: Rubikas R, Maaliki AR (2012) Urgent Thoracotomy for Blunt Chest Trauma. J Trauma Treat 1:151. doi:10.4172/2167-1222.1000151

Copyright: (c) 2012 Rubikas R, et al. This is an open-access article distributed under the terms of the Creative Commons Attribution License, which permits unrestricted use, distribution, and reproduction in any medium, provided the original author and source are credited. 
Score (NISS) [23]. Patient's clinical condition was considered to be stable when arterial blood pressure was maintained at $\geq 90 \mathrm{mmHg}$, and spontaneous breathing provided sufficient blood oxygenation using conservative measures and so-called minor thoracic surgery (MTS) procedures (thoracocentesis, tube thoracostomy, etc.). A patient's clinical condition was considered to be unstable when - despite conservative treatment and MTS procedures - arterial blood pressure did not exceed $90 \mathrm{mmHg}$, and tracheal intubation for the ventilation of the lungs was required. The blood volume accumulated in the pleural cavity (hemothorax) was approximately assessed using chest X-ray, ultrasound, or computed tomography. Hemothorax was categorized as minimal $(\leq 500 \mathrm{ml})$, moderate $(500-1500 \mathrm{ml})$, or massive $(>1500 \mathrm{ml})$. Minimal hemothorax (less than $10 \%$ of the circulating blood volume) did not have any direct influence on patients' hemodynamics. Moderate or massive hemothorax exceeding $10 \%$ of the circulating volume almost always resulted in deterioration of patients' hemodynamics (Figure 1). The aeropathic syndrome (subcutaneous emphysema, pneumothorax, and pneumomediastinum) is a common clinical manifestation of BCT, involving injuries of air-containing chest organs. The majority of the patients were successfully treated with MTS procedures or VATS. However, persistent air leakage via chest tubes, increasing clinical signs of the aeropathic syndrome along with progressing pulmonary failure were indications for UT (Figure 2).

\section{Collection of data and statistical analysis}

Personal details that might disclose the identity of the patients were omitted. Perioperative events included those occurring within 30-days following UT. During the study, we recorded patients' age and gender, the mechanism of injury, functional condition, injuries of the chest wall and intrathoracic organs, traumatic syndromes, NISS, methods of treatment, mortality, and morbidity. NISS and patients age are presented as mean with standard deviation and range. The

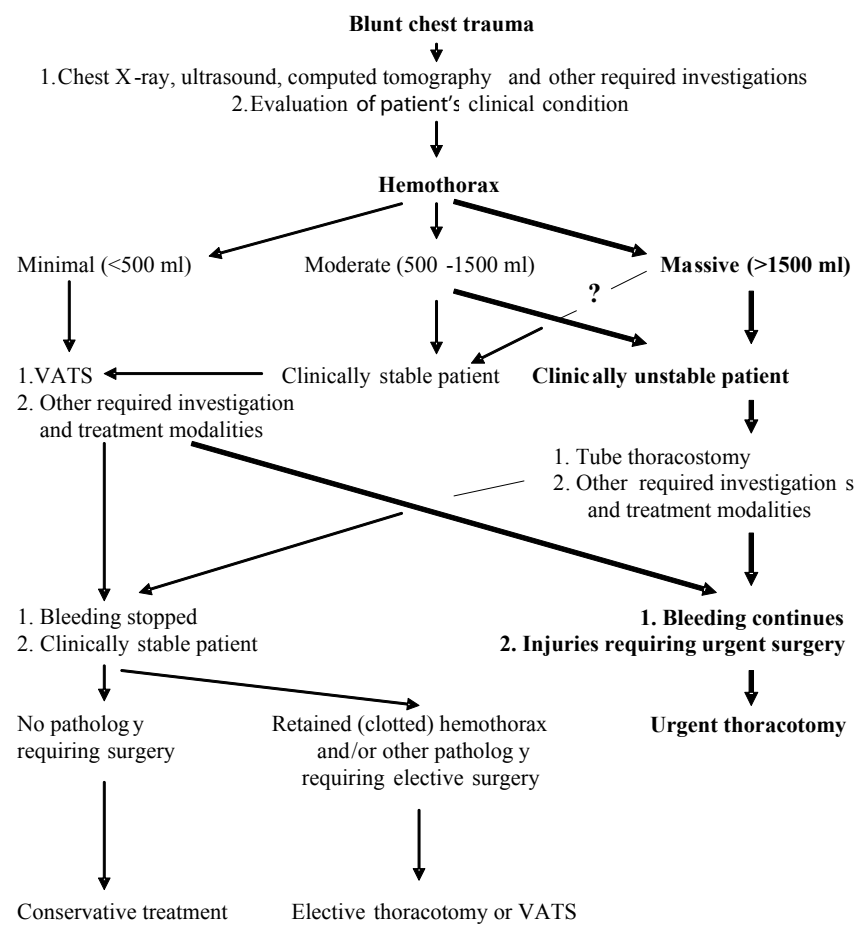

Figure 1: Algorithm for management of the blunt chest trauma complicated with emothorax.

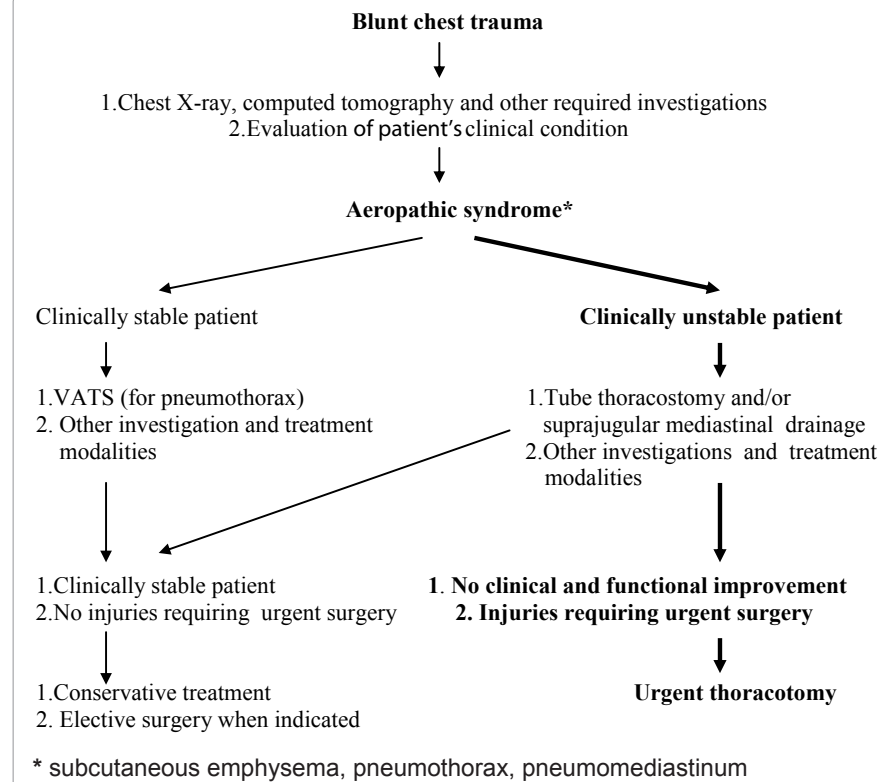

Figure 2: Algorithm for management of blunt chest trauma complicated with aeropathic syndrome.

other variables are presented as number of cases and percentage. Standard statistical tests (Student's $t$ and chi-squared) were used for the comparison of the data. The level of statistical significance was set at $\mathrm{P}<0.05$. Permission from the Local Ethics Committee for a retrospective study is not required in our country.

\section{Results}

Patients, who underwent urgent thoracotomy, profile of the 1,826 patients, 102 (5.6\%), underwent UT (Table 1). In 18.6\% (19/102) of cases, the treatment was started in regional hospitals, and thus these patients were admitted to our Clinic within 6-15 hours following the trauma accident. BCT without associated injuries sustained $71.5 \%(73 / 102)$ of patients. Polytrauma involving BCT and associated abdominal injuries were diagnosed in 12, cerebral injuries - in 10, and injuries of pelvis and/or lower extremities - in 7 patients. There wasn't statistically significant $(\mathrm{p}=0.33)$ difference in age of patients, who sustained isolated BCT $(39.03 \pm 12.16$, range $18-79$ years $)$ and polytrauma ( $43.51 \pm 14.96$, range 19-74). However, there was statistically significant $(\mathrm{p}=0.04)$ difference in age of patients, who underwent UT in clinically stable (40.98 \pm 11.72 , range 19-77 years) and unstable ( $47.83 \pm 16.39$, range 18-79 years) condition. Trauma severity scoring revealed a statistically significant difference between groups of patients: NISS was $19.3 \pm 3.8$ (range 16-29) for clinically stable $62(60.8 \%)$ patients, and $27.1 \pm 8.8$ (range 25-47)-for clinically unstable 40 (39.2\%) patients ( $p=0.001$ ).

\section{Urgent thoracotomy in clinically stable patients}

A clinically stable condition of 62 patients allowed us to examine them thoroughly, therefore, the preoperative period ( $6-10$ hours) in comparing with group of clinically unstable patients was longer. This allowed for adequate diagnostics: no preoperatively undiagnosed severe injuries were revealed on the exploration of the chest. In 17 (27.4\%) of these patients, an urgent surgical intervention was started with VATS, but was then converted to thoracotomy. The indications for UT were based on the evidence of continued intrapleural hemorrhage in $26(41.9 \%)$ patients, persistent air leakage via chest tubes along with increasing signs of the aeropathic syndrome - in $6(9.7 \%)$ patients, 


\begin{tabular}{|c|c|c|}
\hline Patients data & $\begin{array}{c}\text { Blunt chest trauma } \\
(\mathrm{N}=73)\end{array}$ & $\begin{array}{c}\text { Polytrauma* } \\
(\mathrm{N}=29)\end{array}$ \\
\hline Male & 57 & 16 \\
\hline Female & 16 & 13 \\
\hline Age (years) & 3 & 1 \\
\hline $18-20$ & 16 & 3 \\
\hline $21-30$ & 24 & 9 \\
\hline $31-40$ & 14 & 8 \\
\hline $41-50$ & 10 & 5 \\
\hline $51-60$ & 4 & 1 \\
\hline $61-70$ & 2 & 2 \\
\hline $71-79$ & 25 & 14 \\
\hline Time from trauma incidence till hospital admission (hours)
\end{tabular}

* blunt chest trauma and associated injuries of other body regions।

Table 1: Patients, who underwent urgent thoracotomy.

injuries of thoracic organs that should be treated surgically without fail - in $12(19.4 \%)$ patients, and a combination of several causes - in 18 (29.0\%) of 62 patients (Table 2).

Antero-lateral thoracotomy (in two cases - bilateral) was performed in $15(24.2 \%)$ patients, and postero-lateral thoracotomy - in $47(75.8 \%)$ patients. Organ-sparing techniques - like osteosynthesis and fixation of ribs and/or sternum, suture of pulmonary lacerations or stapled wedge resection, or repair of diaphragmatic, bronchial, tracheal, or pericardial tears - were commonly used. Only 2 patients underwent lobectomy of a severely damaged lung. All patients who were operated on while being in a clinically stable condition before UT survived the operation.

\section{Urgent thoracotomy for clinically unstable patients}

Forty clinically unstable patients in whom indications for UT were obvious or highly suspicious were transferred from emergency unit to operating room. Necessary investigations, MTS procedures, and attempts to stabilize the patients' clinical condition were simultaneously undertaken. We had to decline VATS because these patients were unable to tolerate single-lung ventilation and lateral position on the operating table. Among the indications, UT predominated traumatic syndromes that resulted in the patients' unstable clinical condition (Table 2). In all cases, antero-lateral thoracotomy was started within 1-4 hours after the patients' admission to the Clinic. The limited length of preoperative period influenced the quality of diagnostics: many injuries of intrathoracic organs were revealed only on the exploration of the chest.

\section{Outcomes of urgent thoracotomy}

One clinically unstable patient, who was operated for bilateral multiple fractures of ribs and sternum, lesions of intercostal arteries, lung contusion, left-sided massive and right-sided moderate hemothorax died during urgent surgery.

The overall post-operative morbidity rate was $65.7 \%$ (Table 3 ). The most dangerous complications were pneumonia (42 patients), ARDS (17 patients), air leakage (15 patients), hemothorax (11 patients), pleural empyema ( 9 patients), wound infections ( 7 patients), and multiple organ failure (6 patients). An urgent re-thoracotomy due to postoperative bleeding or continued air leakage was performed in 5 and 2 cases, respectively. Five patients underwent elective re-thoracotomy for clotted hemothorax following UT.
The overall postoperative mortality was $7.9 \%$ (8 of 101 patients) However, it was significantly $(p<0.0001)$ different in groups of clinically stable $(0 \%$,$) and unstable (25.1 \%)$ patients. All 8 patients, who died within 30 -days following UT, were operated on being in a clinically unstable condition due to flail chest, lacerations of lungs, moderate or massive hemothorax, and/or the aeropathic syndrome. The main causes of patients' death were bilateral pneumonia (3 patients), ARDS (3 patients), and multiple organ failure ( 2 patients).

\section{Discussion}

It is not only in thoracic surgery, but also in other areas of urgent surgery there exists a common concern that an optimal diagnostics and treatment strategy based on the evaluation of the severity of injuries and on the patient's clinical condition is of great importance $[4,19,20,24]$. The practical issues of the surgical treatment of BCT, compared to its tactical problems, are clearer. Conservative treatment, MTS procedures, VATS or elective thoracotomy are the methods of choice in clinically stable patients. Some reliable methods of diagnostics and repair of the damaged organs have remained in clinical practice for many years [25-29].

In our clinical practice, diagnostics and treatment protocols represented in the form of algorithms proved to be an effective methodic tool in providing urgent surgery for patients who sustained BCT. The evaluation of patients' clinical condition was being the initial action using these algorithms in each individual case. We considered the ability to maintain hemodynamics and respiratory functions on an appropriate level using conservative measures and MTS procedures to be the borderline between patient's clinically stable and unstable condition. Urgent management of functionally unstable patients is more complicated because of time limitations for decision-making, and requirements for advanced anesthetic support and surgical skills (urgent exploration of the chest, damage control, and definitive repair techniques).

\begin{tabular}{|c|c|c|c|c|c|}
\hline Injuries & $\begin{array}{l}\text { Clinically } \\
\text { stable } \\
\text { patients } \\
(\mathrm{N}=62)\end{array}$ & $\begin{array}{l}\text { Clinically } \\
\text { unstable } \\
\text { patients } \\
(\mathrm{N}=40)\end{array}$ & & & \\
\hline & $\mathbf{n}$ & $\%$ & $\mathbf{n}$ & $\%$ & $p$ \\
\hline Blunt chest trauma & 41 & 66.1 & 32 & 80 & 0.19 \\
\hline Polytrauma & 21 & 33.9 & 8 & 20 & 0.24 \\
\hline Minimal hemothorax & 26 & 44.9 & 2 & 5 & 0.0001 \\
\hline Moderate hemothorax & 36 & 58.1 & 10 & 25 & 0.002 \\
\hline Massive hemothorax & - & 0 & 28 & 70 & 0.0001 \\
\hline Aeropathic injuries & 52 & 83.9 & 31 & 77.5 & 0.61 \\
\hline Flail chest & 7 & 11.3 & 24 & 60 & 0.001 \\
\hline $\begin{array}{l}\text { Hemoperitoneum } \\
\text { injuries }\end{array}$ & 4 & 6.5 & 8 & 20 & 0.06 \\
\hline Ribs/stemum & 60 & 96.8 & 39 & 97.5 & 0.74 \\
\hline lungs & 44 & 71 & 29 & 72.5 & 0.99 \\
\hline Diaphragm & 17 & 27.4 & 4 & 17.5 & 0.41 \\
\hline Large Bronchi & 1 & 1.6 & 3 & 7.5 & 0.34 \\
\hline Trachea & - & 0 & 2 & 5 & 0.29 \\
\hline Esophagus & 2 & 3.2 & 1 & 2.5 & 0.55 \\
\hline Pericardium & 1 & 1.6 & - & 0 & 0.97 \\
\hline brain & 5 & 8.1 & 5 & 12.5 & 0.62 \\
\hline Abdominal organs & 4 & 6.5 & 8 & 20 & 0.11 \\
\hline $\begin{array}{l}\text { Pelvis and/or lower } \\
\text { extremities }\end{array}$ & 2 & 3.2 & 5 & 12.5 & 0.14 \\
\hline
\end{tabular}

Table 2: Injuries found on urgent thoracotomy. 


\begin{tabular}{|l|c|c|c|c|c|}
\hline Injuries & $\begin{array}{c}\text { Patients with } \\
\text { postoperative } \\
\text { complications } \\
\text { (N = 67) }\end{array}$ & $\begin{array}{c}\text { Patients without } \\
\text { postoperative } \\
\text { complications } \\
\text { (N = 35) }\end{array}$ & & & \\
\hline $\begin{array}{l}\text { Blunt chest } \\
\text { trauma }\end{array}$ & $\mathbf{n}$ & $\mathbf{\%}$ & $\mathbf{n}$ & $\%$ & $\mathbf{p}$ \\
\hline Polytrauma & 18 & 26.9 & 11 & 31.4 & 0.84 \\
\hline Stable condition & 31 & 46.2 & 31 & 88.2 & 0.0001 \\
\hline Unstable condition & 36 & 53.8 & 4 & 11.4 & 0.0001 \\
\hline $\begin{array}{l}\text { blood loss (<1500 } \\
\text { ml) }\end{array}$ & 29 & 43.30 & 21 & 76 & 0.15 \\
\hline $\begin{array}{l}\text { blood loss (> 1500 } \\
\text { ml) }\end{array}$ & 26 & 38.8 & 4 & 11.4 & 0.007 \\
\hline Aeropathic & 55 & 82.1 & 28 & 80 & 0.6 \\
\hline Flail chest & 26 & 38.8 & 5 & 14.3 & 0.04 \\
\hline $\begin{array}{l}\text { Hemoperitoneum } \\
\text { injuries }\end{array}$ & 5 & 7.5 & 7 & 10.4 & 0.97 \\
\hline $\begin{array}{l}\text { Ribs and / or } \\
\text { stemum }\end{array}$ & 65 & 97 & 34 & 97.1 & 0.78 \\
\hline $\begin{array}{l}\text { Other chest } \\
\text { organs }\end{array}$ & 21 & 31.3 & 10 & 28.6 & 0.93 \\
\hline Brain & 7 & 10.4 & 3 & 8.6 & 0.84 \\
\hline Abdominal organs & 9 & 13.4 & 3 & 8.6 & 0.78 \\
\hline $\begin{array}{l}\text { Pelvis and/or } \\
\text { lower extremities }\end{array}$ & 5 & 7.5 & 2 & 5.7 & 0.84 \\
\hline & 79 & & 24 & 0.84 \\
\hline
\end{tabular}

Table 3: Risk factors of postoperative complications.

In terms of urgency, all surgical interventions are categorized as resuscitative, urgent, or elective. Resuscitative thoracotomy is meant for damage control in the emergency department as an integral part of the resuscitation. Mostly, this type of thoracotomy is undertaken in penetrating chest trauma [16,30-32]. In the two decades, resuscitative thoracotomy for BCT is considered with more rationality than in previous times, when it was subjected to similar indications for both penetrating and blunt chest trauma [33]. Thoracotomy that is undertaken in an acute phase of BCT is defined as urgent in the vast majority of cases. Usually, UT is performed in a well-equipped operating room under controlled conditions $[17,18,20]$.

In general, the indications for UT could be defined as nosologic (preoperatively diagnosed injuries that should be treated surgically without fail), syndromic (life-threatening syndromes - first of all, massive hemorrhage and/or air leakage), and combined, involving both the aforementioned groups of indications. These are not solely theoretical considerations. Situations requiring a surgeon's decision to explore the chest urgently based only on the evidence of lifethreatening syndromes frequently occur in BCT management. Every effort made to diagnose exactly all chest injuries before urgent surgery leads to improper wasting of valuable time. Ignoring this statement or overestimating the possibilities of VATS might result in a false decision and delayed UT, which could deteriorate the patient's health, or even be life-threatening.

\section{Conclusions}

The protocol provided in the form of algorithms proved to be suitable methodic tool to organize urgent surgery for patients who sustained BCT. The determinant factors for decision-making were patient's clinical condition, chest injuries, intrapleural hemorrhage (hemothorax), and/or air leakage (the aeropathic syndrome).VATS has reduced the incidence rate of UT up to $5.6 \%$. However, UT remains an unavoidable surgical approach for clinically unstable patients.

Patient's unstable condition, multiple fractures of ribs and/or sternum causing flail chest, lung injuries, and moderate or massive hemothorax were the main factors influencing patients' morbidity and mortality following UT.

\section{Conflict of Interest}

Authors had no financial and personal relationships with other people and organizations that could have inappropriately influenced their work.

\section{References}

1. Athanassiadi K, Gerazounis M, Theakos N (2004) Management of 150 flail chest injuries: analysis of risk factors affecting outcome. Eur $\mathrm{J}$ Cardiothorac Surg 26: 373-376.

2. Cothren C, Moore EE, Biffl WL, Franciose RJ, Offner PJ, et al. (2002) Lung sparing techniques are associated with improved outcome compared with anatomic resection for severe lung injuries. J Trauma 53: 483-487.

3. Liman ST, Kuzucu A, Tastepe AI, Ulasan GN, Topcu S (2003) Chest injury due to blunt trauma. Eur J Cardiothorac Surg 23: 374-378.

4. McGillicuddy D, Rosen P (2007) Diagnostic dilemmas and current controversies in blunt chest trauma. Emerg Med Clin North Am 25: 695-711.

5. Nirula R, Diaz JJ Jr, Trunkey DD, Mayberry JC (2009) Rib fracture repair: indications, technical issues, and future directions. World J Surg 33:14-22.

6. Vodicka J, Spidlen V, Safranek J, Simanek V, Altman P (2007) Schwerwiegende Brustkorb verletzungen - Erfahrungen mit der operativen Behandlung (Severe chest injuries - experience with surgical therapy). Zentralbl Chir 132: 542-546.

7. Weyant MJ, Fullerton DA (2008) Blunt thoracic trauma. Sem Thorac Cardiovasc Surg 20: 26-30.

8. Ambrogi MC, Lucchi M, Dinni P, Mussi A, Angeletti CA (2002) Videothoracoscopy for evaluation and treatment of hemothorax. J Cardiovasc Surg (Torino) 43 109-112.

9. Carrillo EH, Richardson JD (2005) Thoracoscopy for the acutely injured patient. Am J Surg 190: 234-238

10. Cetindag IB, Neideen T, Hazelrigg SR (2007) Video-assisted Thoracic Surgical applications in thoracic trauma. Thoracic Surg Clin 17: 73-79.

11. Darlong LM (2010) Thoracoscopy for trauma. Eur J Trauma Emerg Surg 36:15 18.

12. Lang-Lazdunski L, Mouroux J, Pons F, Grosdidier G, Martinod E, et al. (1997) Role of videothoracoscopy in chest trauma. Ann Thorac Surg 63: 327-333.

13. Mineo TC, Ambrogi V, Christino B, Pompeo E, Pistolese C (1999) Changing indications for thoracotomy in blunt chest trauma after the advent of videothoracoscopy. J Trauma 47: 1088-1091.

14. Spann JC, Nwariaku FE, Wait M (1995) Evaluation of video-assisted thoracoscopic surgery in the diagnosis of diaphragmatic injuries. Am J Surg 170: 628-631.

15. Balkan ME, Oktar GL, Kayi-Cangir A, Ergul EG (2002) Emergency thoracotomy for blunt thoracic trauma. Ann Thorac Cardiovasc Surg 8:78-82.

16. Hunt PA, Greaves I, Owens WA (2006) Emergency thoracotomy in thoracic trauma-a review. Injury 37: 1-19.

17. Kish G, Kozloff L, Joseph WL, Adkins PC (1976) Indications for early thoracotomy in the management of chest trauma. Ann Thorac Surg 22: 23-28.

18. Mattox KL (1989) Indications for thoracotomy: deciding to operate. Surg Clin North Am 69: 47-58.

19. Meredith JW, Hoth JJ (2007) Thoracic trauma: when and how to intervene. Surg Clin North Am 87: 95-118

20. Wall Jr MJ, Storey JH, Mattox KL (2000) Indications for thoracotomy. In: Mattox KL, Feliciano DV, Moore EE, editors. Trauma. (4thedn), McGraw-Hill, New York.

21. Rubikas R, Kunigèlis G, Bagdonas $E$ (1997) Emergency thoracic surgery in the treatment of chest trauma. Acta medica Lithuanica 4:70-73.

22. Rubikas R (2000) Urgentinè torakalinè chirurgija (Urgent thoracic surgery) Kaunas: Publishing house of Kaunas University of Medicine, (in Lithuanian).

23. Osler T, Baker SP, Long W (1997) A modification of the injury severity score that both improves accuracy and simplifies scoring. J Trauma 43: 922-926. 
24. Domino KB (1996) Pulmonary function and dysfunction in the traumatized patient. Anesthesioly Clin 14: 59-84.

25. Besson A, Saegesser F (1983) Color atlas of chest trauma and associated injuries, vol. 1, Oradell, NJ, Medical Economics.

26. Fitzgerald M, Gocentas R (2004) Chest trauma. In: Cameron P, Jelinek G, Kelly A-M, et al., (Eds.), Textbook of adult emergency medicine. 2nd ed., Edinburgh, Churchill Livingstone.

27. Huber-Wagner S, Kõrner M, Ehrt A, Kay MV, Pfeifer KJ, et al. (2007) Emergency chest tube placement in trauma care-which approach is preferable? Resuscitation 72: 226-233.

28. Meyer DM (2007) Hemothorax related to trauma. Thorac Surg Clin 17: 47-55.
29. Miller DL, Mansour KA (2007) Blunt traumatic lung injuries. Thorac Surg Clin 17: 57-61.

30. Phelan HA, Patterson SG, Hassan MO, Gonzalez RP, Rodning CB (2006) Thoracic damage-control operation: principles, techniques, and definitive repair. J Am Coll Surg 203: 933-941.

31. Rotondo MF, Bard MR (2004) Damage control surgery for thoracic injuries. Injury 35: 649-654.

32. Ozyurtkan MO, Balci AE, Cakmak M (2010) Thoracotomy in thoracic injuries: results from a tertiary referral hospital. Eur J Trauma Emerg Surg 3: 233-239.

33. Boyd M, Vanek VW, Burguet CC (1992) Emergency room resuscitative thoracotomy: when is it indicated? J Trauma 33: 714-721. 